\title{
Aerosol optical characteristics and their vertical distributions under enhanced haze pollution events: effect of the regional transport of different aerosol types over eastern China
}

Tianze Sun et al.

Correspondence to: Huizheng Che (chehz@camscma.cn) and XiangaoXia (xxa@mail.iap.ac.cn)

The copyright of individual parts of the supplement might differ from the CC BY 4.0 License. 

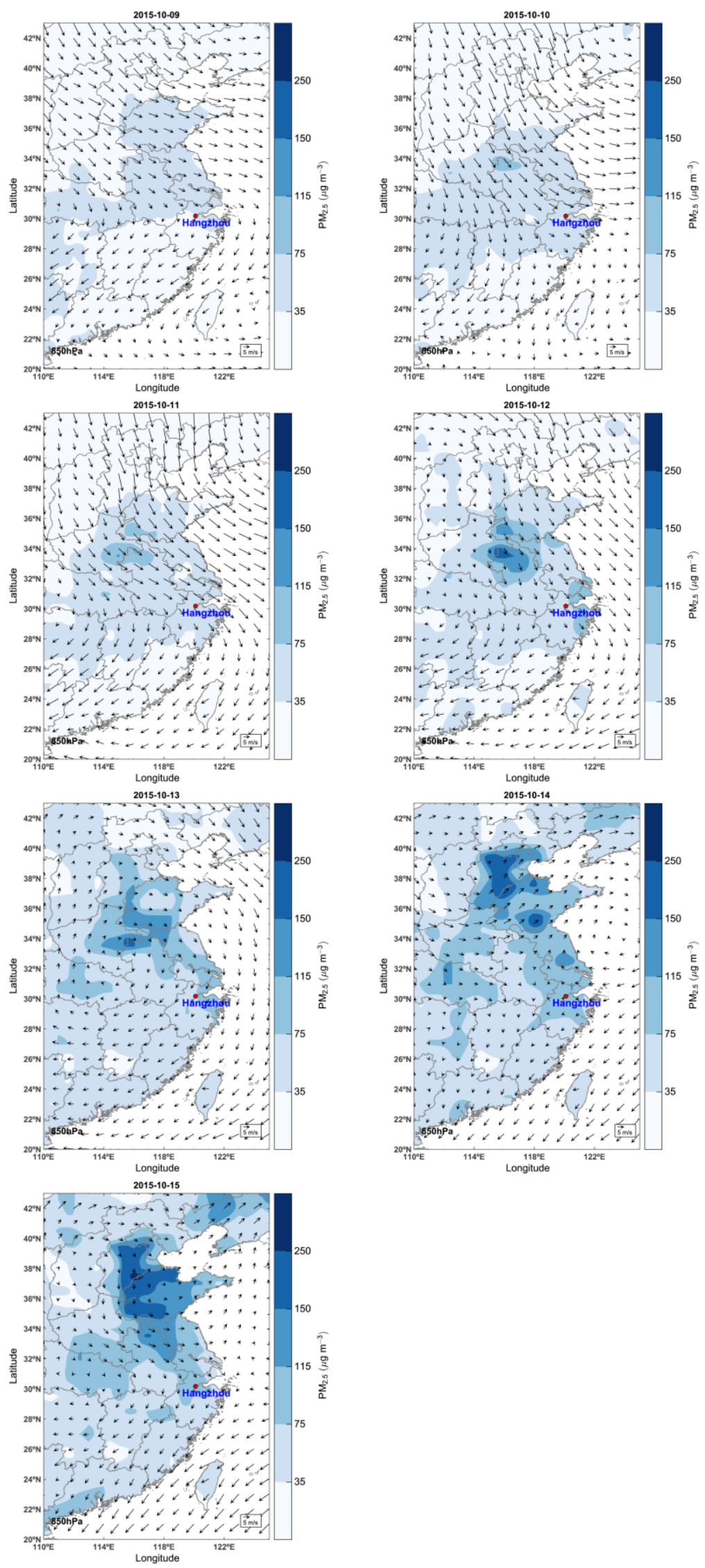

Figure S1. Daily averaged spatial distribution of $\mathrm{PM}_{2.5}$ mass concentration and the wind field at $850 \mathrm{hPa}$ from ECMWF over eastern China during 09-15 October, 2015. 

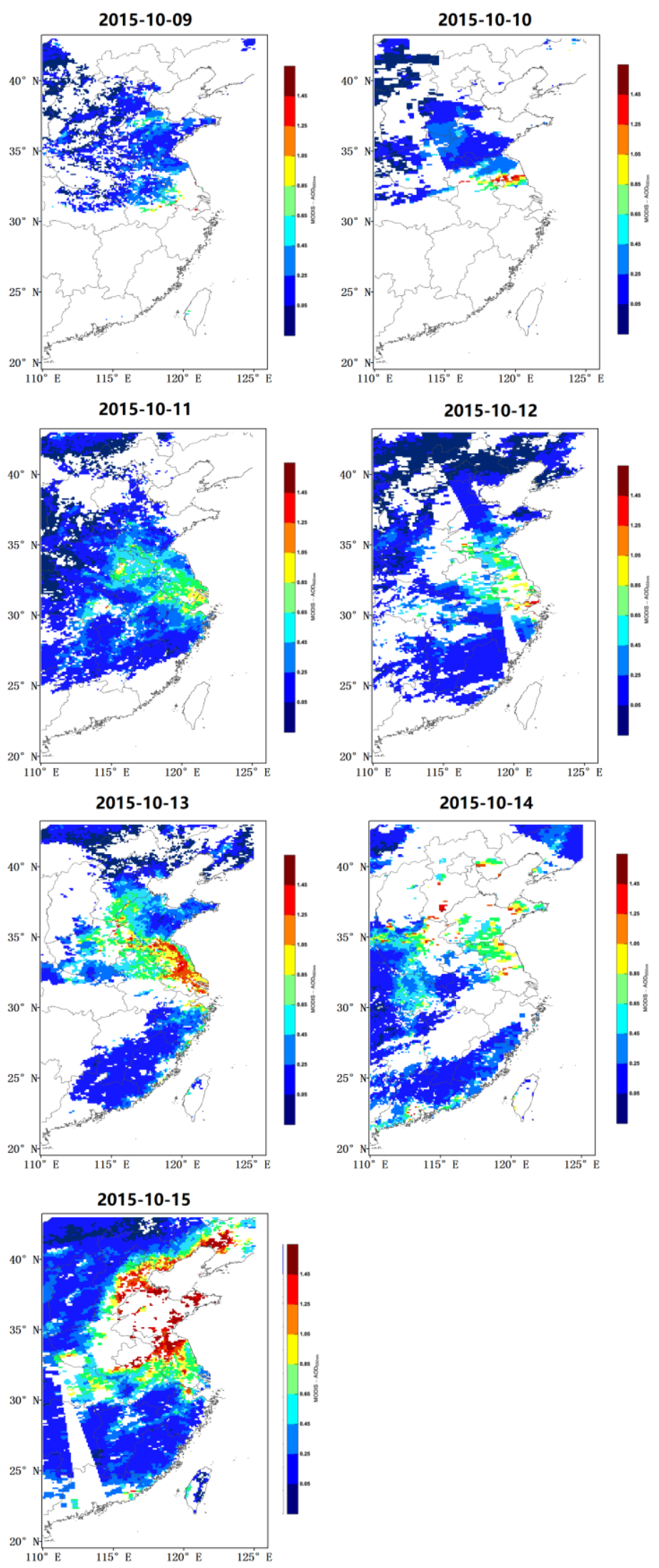

Figure S2. Daily averaged spatial distribution of AOD from MODIS, over eastern China during 09-15 October, 2015. 

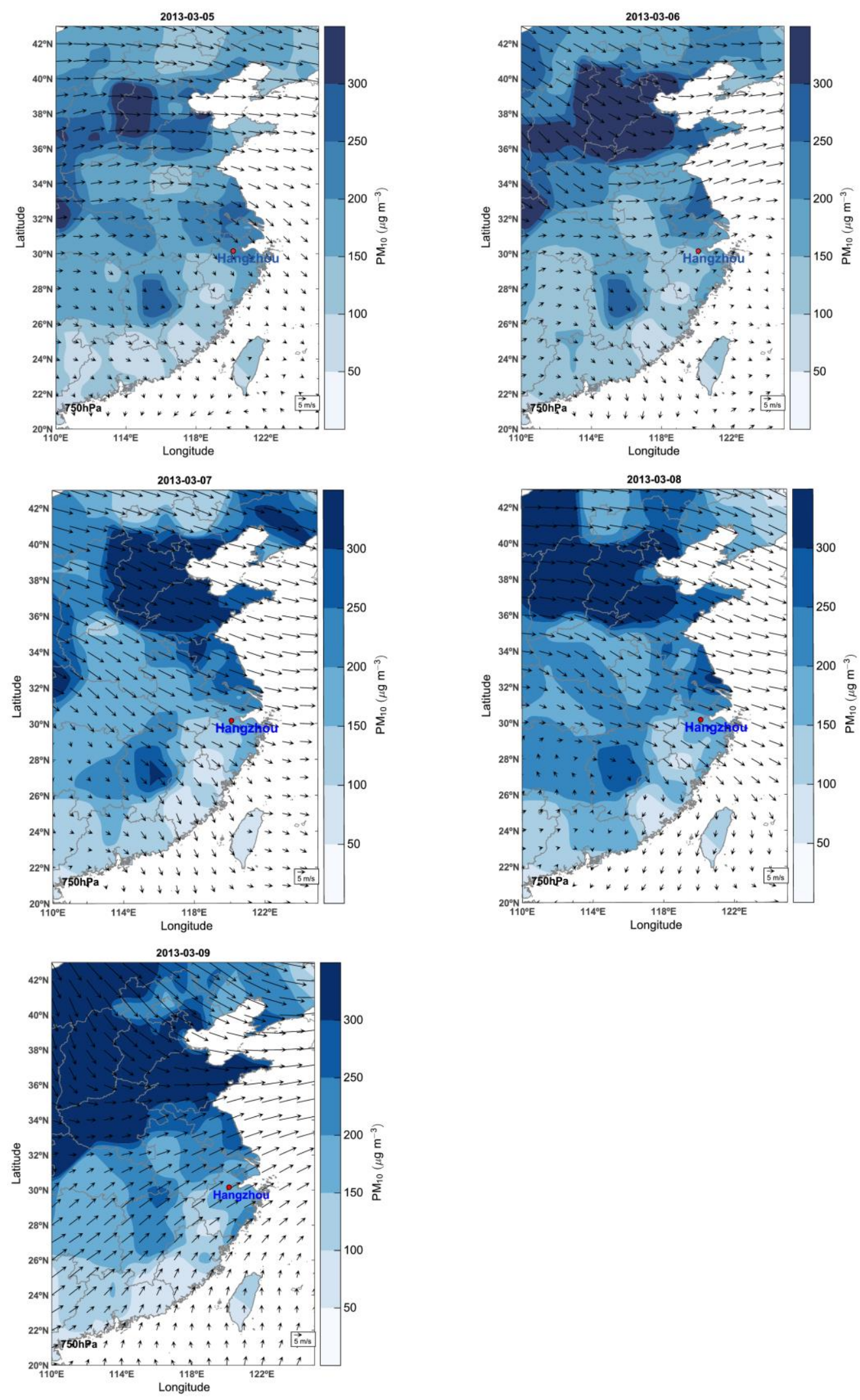

Figure S3. Daily averaged spatial distribution of $\mathrm{PM}_{10}$ mass concentration and the wind field at 750hPa from ECMWF over eastern China, during 05-09 March, 2013. 

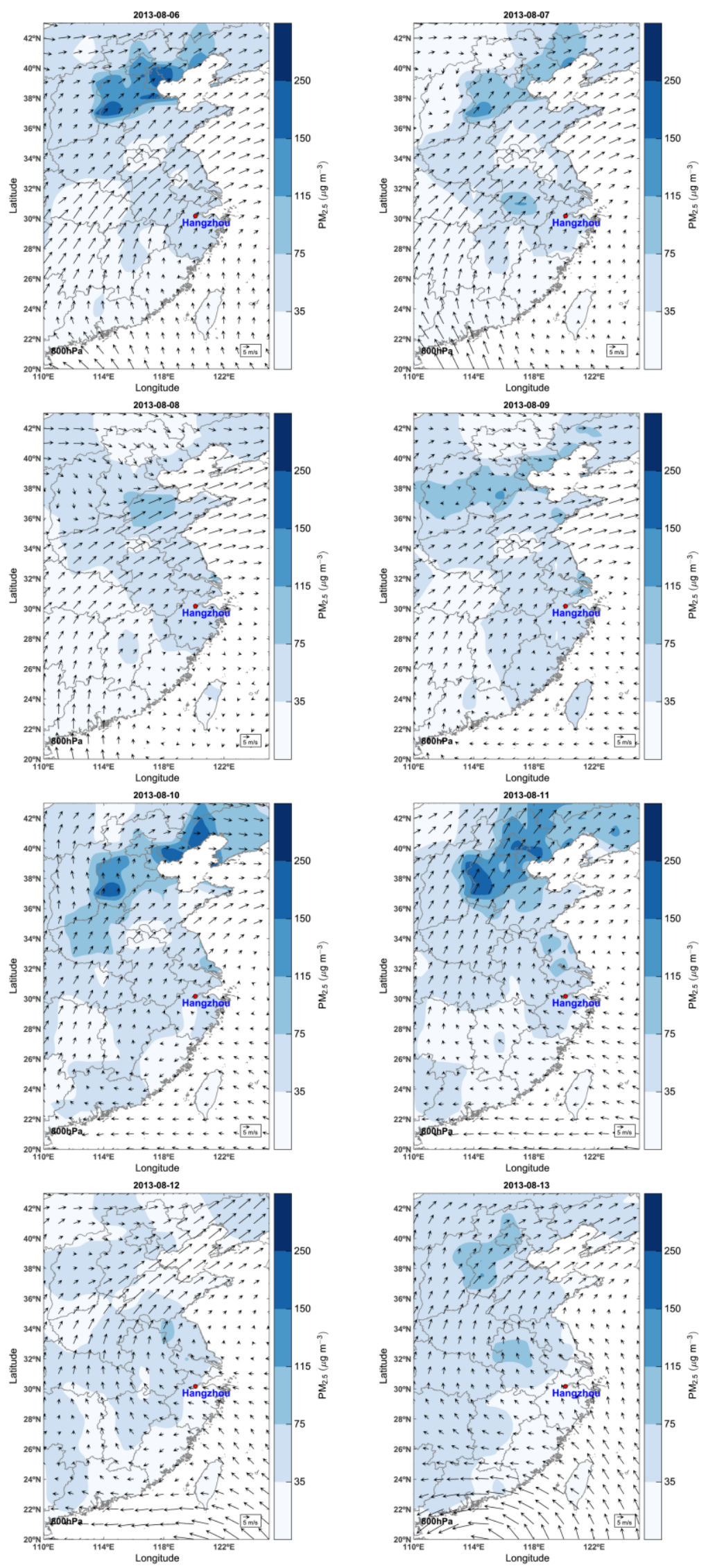

Figure S4. Daily averaged spatial distribution of $\mathrm{PM}_{2.5}$ mass concentration and the wind field at 800hPa from ECMWF over eastern China, during 06-13 August, 2013. 

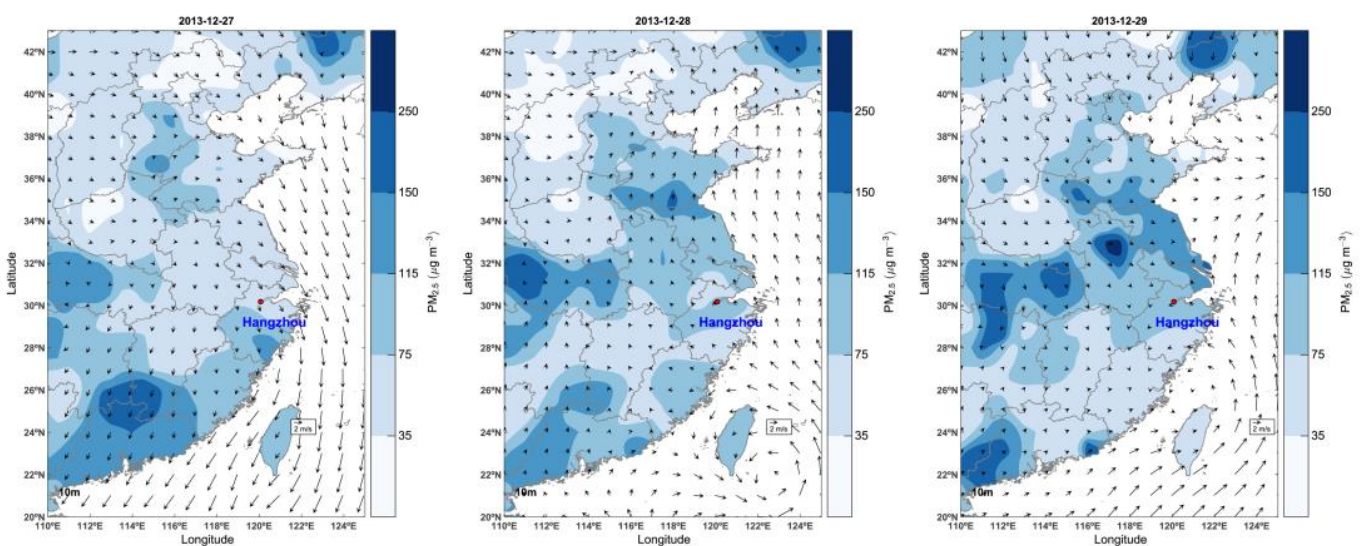

Figure S5. Spatial distribution of $\mathrm{PM}_{2.5}$ and the wind field at $10 \mathrm{~m}$ from ECMWF over eastern China, during 27-29 December, 2013. 